\title{
Dispersive Solid-Phase Extraction Using 3-Mercaptopropyltrimethoxysilane Functionalized Magnetic MWCNT-Based Nanocomposite for Selective and Efficient Preconcentration of $\mathrm{Pb}^{2+}$ with FAAS Determination
}

\author{
Paula M. dos Santos, ${ }^{\oplus a, b}$ César R. T. Tarley ${ }^{\circledR *, b, c}$ and Marcela Z. Corazza ${ }^{a}$ \\ ${ }^{a}$ Faculdade de Ciências Exatas e Tecnologia, Universidade Federal da Grande Dourados, \\ Rod. Dourados-Itahum, Km 12, Cidade Universitária, 79804-970 Dourados-MS, Brazil \\ ${ }^{b}$ Departamento de Química, Universidade Estadual de Londrina, Rod. Celso Garcia Cid, \\ PR 445 km 380, Campus Universitário, 86051-990 Londrina-PR, Brazil \\ ${ }^{c}$ Departamento de Química Analítica, Instituto de Química, \\ Instituto Nacional de Ciência e Tecnologia (INCT) de Bioanalítica, \\ Universidade Estadual de Campinas (UNICAMP), Cidade Universitária Zeferino Vaz s/n, \\ 13083-970 Campinas-SP, Brazil
}

\begin{abstract}
A novel nanocomposite based on magnetic multiwalled carbon nanotubes coated with $\mathrm{SiO}_{2}$ and functionalized with 3-mercaptopropyltrimethoxysilane (3-MPTMS) was prepared for the efficient extraction and quantification of lead ions from water samples. The adsorption capacity of this adsorbent could reach $1.995 \mathrm{mg} \mathrm{g}^{-1} \mathrm{~Pb}^{2+}$ in an equilibrium time of $30 \mathrm{~min}$. Under optimized conditions derived using the $2^{5-1}$ fractional factorial design, a $45 \mathrm{~mL}$ aliquot of the sample was preconcentrated onto $90 \mathrm{mg}$ of nanocomposite during $4 \mathrm{~min}$. The lead ions adsorbed on the nanocomposite were eluted using $2 \mathrm{~mol} \mathrm{~L}^{-1} \mathrm{HNO}_{3}$. The proposed method provided a preconcentration factor of 15.25 times, yielding limits of detection (LOD) and quantification (LOQ) of 0.56 and $1.86 \mu \mathrm{g} \mathrm{L}^{-1}$, respectively, and a linear range between 1.86 and $100.00 \mu \mathrm{g} \mathrm{\textrm {L } ^ { - 1 }}$. The relative standard deviations (RSD, $\mathrm{n}=10$ ), determined using solutions of $\mathrm{Pb}^{2+}$ at 10 and $120 \mu \mathrm{g} \mathrm{L}^{-1}$, were 2.3 and $2.1 \%$, respectively. A high tolerance toward potentially foreign ions was observed. The proposed method was successfully applied to the rapid extraction of $\mathrm{Pb}^{2+}$ ions from different water samples, confirming good recovery values (90.33-109.53\%); the accuracy of the method was evaluated through graphite furnace atomic absorption spectrometry (GF AAS) as a reference technique.
\end{abstract}

Keywords: lead, magnetic multiwalled carbon nanotubes, 3-mercaptopropyltrimethoxysilane, magnetic solid-phase extraction (MSPE)

\section{Introduction}

Lead is among the three most toxic metals in the world. The introduction of potentially toxic elements into the environment occurs through natural and anthropogenic sources, and is extremely dangerous, as the metals are not metabolized by the body and accumulate in various tissues of the human body, causing physiological, blood, and brain disorders, besides damage to the bones, kidneys, liver, and immune system. ${ }^{1-4}$ Lead is typically present in products widely used in our daily life, such as batteries, cosmetics, gasoline, and electroplating products. Therefore,

*e-mail: tarley@uel.br

Editor handled this article: Eduardo Carasek in recent decades, priority has accorded to monitoring this element in water samples, considering acceptable levels recognized by regulatory bodies such as the World Health Organization (WHO) ${ }^{5}$ and the Ministry of Health of Brazil (MHB), together with the National Environment Council (CONAMA, 2005), which, via Resolution No. $357 / 2005^{6}$ established that the maximum allowable concentration of lead allowed for fresh water is $10.0 \mu \mathrm{g} \mathrm{L} \mathrm{L}^{-1}$. The determination of this metallic ion has been achieved typically via spectrometric techniques, especially the flame atomic absorption spectrometry (FAAS), due to its relevant simplicity, low cost, and ease of operation with rapid and acceptable responses. ${ }^{7}$ However, due to the low levels of $\mathrm{Pb}^{2+}$ in most samples and the low sensitivity of FAAS, it is necessary to employ separation/preconcentration steps 
to improve the detectability of the method, in addition to ensuring the selectivity of the proposed method; this is because direct methods are laborious due to interference from many chemicals in the sample matrix and/or the low limit of detection of most analytical techniques, such as FAAS. ${ }^{8,9}$

Among the separation/preconcentration methods, magnetic dispersive solid-phase extraction (MDSPE), introduced by Šafaříková and Šafařík in $1999,{ }^{10}$ has proven to be a quick and easy preconcentration method, where the analyte is directly separated from large sample volumes through the use of magnetic adsorbents, without steps such as centrifugation and/or filtration. ${ }^{10,11}$ For this, $\mathrm{Fe}_{3} \mathrm{O}_{4}$ particles has excelled as magnetic cores due to their biocompatibility, high potential of application and for offering multiple functionalization routes for chemical synthesis. ${ }^{10}$

However, the lack of selectivity and possibility of oxidation of these magnetic materials under severe conditions of analysis make them unsuitable for application as adsorbents in complex matrix samples. ${ }^{12}$ Therefore, in recent years, different types of coatings and/or decorations have been proposed for magnetic nanoparticles to overcome these disadvantages. Among the main types of coatings used to protect magnetic nanoparticles, coatings $\mathrm{SiO}_{2}$ stand out not only by increase the chemical stability of these nanoparticles, but also increase their adsorption capacity and selectivity, since they allow additional modification/functionalization by numerous modifying agents. Allied to this, the use of carbon nanotubes as a support/coating in the formation of magnetic materials for the analysis of organic and inorganic compounds has been shown to be promising due to the simplicity of the synthesis, to its high surface area and mechanical stability, providing considerable increase in the sensitivity and selectivity of the analysis methods. ${ }^{13,14}$

Khan et al. ${ }^{15}$ reported the applicability of nanocomposites based on multiwalled magnetic carbon nanotubes coated with silica impregnated with 1-(2-pyridylazo)-2-naphthol as an adsorbent for the removal of $\mathrm{Pb}^{2+}$ and $\mathrm{Co}^{2+}$ from water samples sourced from Kayseri, Turkey. The combination of magnetic properties, combined with the structural properties of carbon nanotubes and silica, besides the strong metal-binder interaction, enabled the development of a rapid method (4 min of extraction and desorption), with high sensitivity to low concentrations (limit of detection of 1.76 and $0.55 \mu \mathrm{g} \mathrm{L}^{-1}$ for $\mathrm{Pb}$ and $\mathrm{Co}$, respectively) and high selectivity, since there was no significant interference from cations and anions even at high concentrations. ${ }^{15}$ The high adsorption efficiency of these nanoadsorbers, arising from the type of coating and surface modification, as well as the convenient separation of magnetic materials, were also reported by Ghasemi et al. ${ }^{16}$ In this study, novel and efficient silica-coated magnetic multiwalled carbon nanotube (m-MWCNTs@ $\mathrm{SiO}_{2}$ ) nanoadsorbents functionalized by amino groups were proposed for the removal of $\mathrm{Pb}^{2+}$ and $\mathrm{Cd}^{2+}$ from environmental soil and water samples. The results revealed that there is no significant effect on the adsorption efficiency of $\mathrm{Pb}^{2+}$ and $\mathrm{Cd}^{2+}$ ions even in the presence of large amounts of interference species commonly present in water. Moreover, the method demonstrated high adsorption capacity for ions $\left(89.0 \mathrm{mg} \mathrm{g}^{-1}\right.$ for $\mathrm{Pb}^{2+}$ and $94.5 \mathrm{mg} \mathrm{g}^{-1}$ for $\mathrm{Cd}^{2+}$ ), a fast adsorption rate ( $5 \mathrm{~min}$ ) attributed to the laminated structure of the carbon nanotubes and active adsorption sites on the external surface of the nanoadsorbent, as well as good stability when used for at least twenty cycles. ${ }^{16}$ The decoration of carbon nanotubes with nanoparticles is one of the approaches to optimize their potential application. Accordingly, a magnetic multiwalled carbon nanotube nanocomposite was synthesized and used as the adsorbent for the preconcentration and determination of $\mathrm{Pb}^{2+}$ and $\mathrm{Mn}^{2+}$ ions in lipstick, rice, and urine samples. Using the batch extraction procedure, stable complexes of 1-(2-pyridilazo)-2-naphtol (PAN) with $\mathrm{Pb}^{2+}$ and $\mathrm{Mn}^{2+}$ ions were adsorbed on the magnetic multiwalled carbon nanotube (m-MWCNT) nanocomposite, achieving low limits of detection $\left(1.0 \mu \mathrm{g} \mathrm{L}^{-1}\right.$ for $\mathrm{Pb}^{2+}$ ions and $0.6 \mu \mathrm{g} \mathrm{L}^{-1}$ for $\mathrm{Mn}^{2+}$ ions) and high enhancement factors (390 for $\mathrm{Pb}^{2+}$ and 697 for $\mathrm{Mn}^{2+}$ ), using solution volumes of 100 and $150 \mathrm{~mL}$, respectively. In addition, the easy regeneration demonstrated to be a significant property of m-MWCNT, once this adsorbent can be reused at least eight times on average without decrease of recovery after wash/clean procedures. ${ }^{17}$ It should also be noted that it is not only the organic and/or inorganic coatings that improve the performance of the magnetic adsorbents. The chemical modification of these nanocomposites with organofunctional silane reagents improves the selectivity and sensitivity significantly, once their functional groups can form complexes with the majority of transition metals. ${ }^{18,19}$ Among them, organosilanes such as 3-(2-aminoethylamino) propyltrimethoxysilane,${ }^{20}$ mercaptopropyltrimethoxysilane (MPTMS), ${ }^{21}$ and 3-aminopropyltriethoxysilane ${ }^{22}$ have demonstrated efficiency in the removal of various toxic elements due to the strong complexation capacity of organosilane groups with the majority metal ions besides the easy regeneration only by proton replacement of the metal ions with acid mineral washing. Although the decoration of carbon nanotubes with iron oxide particles coated with silica functionalized by thiol groups demonstrated relevant advantages as potential adsorbents for toxic elements, there is a scarcity of published literature regarding the assessment 
of the performance of these nanocomposites for $\mathrm{Pb}$ ion preconcentration/determination via dispersive solid-phase microextraction. Therefore, in this study, a novel and efficient magnetic MWCNT-based nanocomposite grafted with 3-mercaptopropyltrimethoxysilane,m-MWCNT@Si-SH, was synthesized and successfully applied for the preconcentration of $\mathrm{Pb}^{2+}$ ions from water samples with posterior determination by FAAS.

\section{Experimental}

\section{Reagents and solutions}

All chemical reagents used in the experiments were of analytical grade. Ultrapure water $(18.2 \mathrm{M} \Omega \mathrm{cm})$ from the Osmose Reversa OS10LXE purification system (Gehaka, São Paulo, SP, Brazil) was used to prepare all solutions. The glassware used were kept in nitric acid solution $10 \%(\mathrm{v} / \mathrm{v})$ for $24 \mathrm{~h}$, for decontamination prior to use. Iron(III) chloride $\left(\mathrm{FeCl}_{3} \cdot 6 \mathrm{H}_{2} \mathrm{O}\right)$, iron(II) chloride $\left(\mathrm{FeCl}_{2} \cdot 4 \mathrm{H}_{2} \mathrm{O}\right)$, multiwalled carbon nanotubes (MWCNTs, purity: 95\%, diameter: 10-40 nm, length: 5-20 $\mu \mathrm{m}$ ), tetraethylorthosilicate (TEOS, $\mathrm{Si}\left(\mathrm{OC}_{2} \mathrm{H}_{5}\right)_{4}$, and 3-mercaptopropyltrimethoxysilane (3-MPTMS) were acquired from Sigma-Aldrich (St. Louis, MO, USA) and used to synthesize the magnetic nanoadsorbent. Ethyl alcohol was acquired from Dinâmica (Diadema, Brazil), while ammonia solution $(28 \%, \mathrm{v} / \mathrm{v})$, nitric acid $(65 \%, \mathrm{v} / \mathrm{v})$, and sulfuric acid $(98 \%)$ were acquired from Vetec (Rio de Janeiro, Brazil). Salts of the cations $\mathrm{Na}^{+}, \mathrm{K}^{+}, \mathrm{Ca}^{2+}, \mathrm{Cd}^{2+}$, $\mathrm{Fe}^{3+}, \mathrm{Cu}^{2+}, \mathrm{Ni}^{2+}$, and $\mathrm{Mn}^{2+}$ were acquired from Synth (São Paulo, Brazil) and used in the interference study. Stock solutions of $\mathrm{Pb}^{2+}\left(1000 \pm 0.006 \mathrm{mg} \mathrm{L}^{-1}\right)$ were obtained from Specsol (Gaithersburg, USA). Working solutions were prepared by the stepwise dilution of the above stock solutions just before use.

\section{Instruments}

A Varian spectrometer (Agilent Technologies, Santa Clara, CA, USA), model AA240FS flame atomic absorption spectrometer equipped with a hollow lead cathode lamp as a radiation source (wavelength: $217.0 \mathrm{~nm}$; current: $10 \mathrm{~mA}$ ), and a deuterium lamp for background correction were used for the analysis. The aspiration flow rate was $5.0 \mathrm{~mL} \mathrm{~min}^{-1}$, the acetylene flow rate was $2.90 \mathrm{~L} \mathrm{~min}^{-1}$, and the air flow rate was $13.50 \mathrm{~L} \mathrm{~min}^{-1}$. The $\mathrm{pH}$ of the samples was measured on a digital $\mathrm{pH}$ meter (model 913) obtained by Metrohm (Herisau, Switzerland) while a vortex agitator (Biomixer, São Paulo, Brazil) was used for the magnetic solid-phase extraction (MSPE). A Fourier transform infrared (FTIR) spectrometer (Jasco FT/IR-4100 type A, Easton, MD 21601, USA), operating in the transmission mode between 4000 and $400 \mathrm{~cm}^{-1}$, was used to elucidate the functional groups present in m-MWCNT@Si-SH. The characteristic morphology of the nanoadsorbent was evaluated using field emission scanning electron microscopy (FE-SEM, TESCANMira 3 model, Brno, South Moravia, Czech Republic). The crystalline structure of the adsorbents was determined through X-ray diffraction (XRD) measurements using a Philips MDR (Grovewood Rd, Malvern, UK) X-ray diffractometer at a current of $35 \mathrm{~mA}$ and voltage of $40 \mathrm{kV}$, with incident X-rays $\left(\lambda=1.54060 \AA\right.$ ) of angle $2 \theta$ varying between 5 and $80^{\circ}$. The textural parameters of the materials were calculated using adsorption-desorption isotherms with nitrogen gas at $77 \mathrm{~K}$ and with relative pressure between ca. $10^{-6}$ and $0.995 \mathrm{~mm} \mathrm{Hg}$, using the Quantachrome Nova 1200e coupled to an automatic gas analyzer (Quantachrome, Boynton Beach, FL, USA). Vibrating sample magnetometry (VSM) was performed using a vibration sample magnetometer system (EG\&G Princeton Applied Research model 4500, Laguna Hills, CA, USA).

\section{Synthesis of the m-MWCNT@Si-SH nanoparticles}

$\mathrm{Fe}_{3} \mathrm{O}_{4}$ nanoparticles were synthesized through the co-precipitation method with minor modification according to the report by Khan et al. ${ }^{15}$ For this, in a round-bottom flask, $52.31 \mathrm{mmol}$ of $\mathrm{FeCl}_{2} \cdot 4 \mathrm{H}_{2} \mathrm{O}$ and $14.80 \mathrm{mmol}$ of $\mathrm{FeCl}_{3} \cdot 6 \mathrm{H}_{2} \mathrm{O}$ were solubilized in $150 \mathrm{~mL}$ of ultrapure water. Then, $20 \mathrm{~mL}$ of $\mathrm{NH}_{4} \mathrm{OH}$ (25-28\%) was added dropwise to this solution and reacted under an inert atmosphere, until a black $\mathrm{Fe}_{3} \mathrm{O}_{4}$ precipitate was formed. The obtained material was washed several times with distilled water and oven-dried for $24 \mathrm{~h}$ at $65^{\circ} \mathrm{C}$. After synthesis of the $\mathrm{Fe}_{3} \mathrm{O}_{4}$ nanoparticles, they were inserted into the hollow cavities of the carbon nanotubes using the following procedure: $1 \mathrm{~g}$ of MWCNT was added to a suspension of $4 \mathrm{~g}$ of $\mathrm{Fe}_{3} \mathrm{O}_{4}$ dispersed in $80 \mathrm{~mL}$ of ethanol at $60{ }^{\circ} \mathrm{C}$ and kept under vigorous agitation and an inert atmosphere of $\mathrm{N}_{2}$, for $5 \mathrm{~h}$. The obtained material (m-MWCNT) was washed with ultrapure water and dried in the oven at $60{ }^{\circ} \mathrm{C}$. In sequence, to cover the magnetite particles, $4.5 \mathrm{~g}$ of $\mathrm{m}-\mathrm{MWCNT}$ were dispersed in $80 \mathrm{~mL}$ of ethanol and $10 \mathrm{~mL}$ of TEOS were added to the solution. The reaction was sustained for $24 \mathrm{~h}$ at basic pH and $80{ }^{\circ} \mathrm{C}$, resulting in m-MWCNT@Si. The material obtained was washed several times with ultrapure water and dried in an oven at $60{ }^{\circ} \mathrm{C}$ for $24 \mathrm{~h}$. Finally, for functionalization of the m-MWCNT@Si nanocomposite, $4.5 \mathrm{~g}$ of m-MWCNT@Si was dispersed in $80 \mathrm{~mL}$ of ethanol, and $10 \mathrm{~mL}$ of 3-MPTMS (pH 4.5) was added sequentially to this mixture. The reaction occurred in an inert atmosphere 
for $2 \mathrm{~h}$. The resulting nanoparticles (m-MWCNT@Si-SH) were washed with ultrapure water and oven-dried at $60^{\circ} \mathrm{C}$.

\section{Adsorption kinetic study}

The adsorption kinetic studies of $\mathrm{Pb}^{2+}$ on m-MWCNT@Si-SH were carried out from batch experiments at room temperature by stirring $20 \mathrm{mg}$ of material with $10.0 \mathrm{~mL}$ of $\mathrm{Pb}^{2+}$ solution at $5.0 \mathrm{mg} \mathrm{L}^{-1}$ concentration for different periods of time (1-90 $\mathrm{min}$ ) in a shaker at $130 \mathrm{rpm}$. The $\mathrm{pH}$ of solutions was set at 4.0. After the stirring time, the material was separated with an external magnetic field and the supernatant was used to determine the amounts of $\mathrm{Pb}^{2+}$ retained in the adsorbent (Qe) according to the following equation:

$\mathrm{Qe}=\frac{\left(\mathrm{C}_{0}-\mathrm{Ce}\right) \times \mathrm{V}}{\mathrm{m}}$

where $\mathrm{C}_{0}$ is the initial $\mathrm{Pb}^{2+}$ concentration $\left(\mathrm{mg} \mathrm{L}^{-1}\right), \mathrm{Ce}$ is the concentration $\left(\mathrm{mg} \mathrm{L}^{-1}\right)$ of the ions at equilibrium, $\mathrm{V}$ is the solution volume (L) and $\mathrm{m}$ is the adsorbent mass $(\mathrm{g})$. The kinetic data were then applied to the common adsorption kinetic models, pseudo-first order, pseudo-second order, Elovich and intraparticle diffusion.

\section{Adsorption isotherms}

In order to obtain the adsorption isotherms, experiments in batch were performed in similar way to the kinetic procedure. $10.0 \mathrm{~mL}$ of $\mathrm{Pb}^{2+}$ solutions with concentrations varying from 0.01 to $55.0 \mathrm{mg} \mathrm{L}^{-1}$ was stirred during $30 \mathrm{~min}$ with m-MWCNT@Si-SH. The most used isotherm models, including Langmuir, Freundlich as well as single and dualsite Langmuir-Freundlich models were applied to fit the data and characterize the metal ion adsorption.

\section{MDSPE procedure}

The parameters that play important roles in MSPE were optimized by means of the $2^{5-1}$ fractional factorial design, as can be observed in Table 1, and their results (absorbance value) were interpreted through the Pareto diagram and processed by the Statistica 10.0 software. ${ }^{23}$ Thus, under optimized conditions obtained from the $2^{5-1}$ fractional factorial design, $45 \mathrm{~mL}$ of sample solution containing $50 \mu \mathrm{g} \mathrm{L}^{-1} \mathrm{~Pb}^{2+}$, adjusted to $\mathrm{pH} 4.0$ using solutions of $\mathrm{HNO}_{3}$ and $1.0 \mathrm{~mol} \mathrm{~L}^{-1}$ of $\mathrm{NaOH}$, was introduced into a $50 \mathrm{~mL}$ conical capped tube containing 90 mg of the m-MWCNT@Si-SH nanocomposite. The mixture was stirred in a vortex shaker for $4 \mathrm{~min}$. After complete adsorption, the nanocomposite was separated from the solution by using an external magnetic field and the $\mathrm{Pb}^{2+}$ ions adsorbed onto the m-MWCNT@Si-SH nanoparticles were eluted using $2.0 \mathrm{~mL}$ of $1.0 \mathrm{~mol} \mathrm{~L}^{-1} \mathrm{HNO}_{3}$ under vortex stirring for $1 \mathrm{~min}$ and measured by FAAS.

Table 1. Parameters and levels studied by fractional factorial design $2^{5-1}$

\begin{tabular}{lcc}
\hline Parameter & $(-)$ & $(+)$ \\
\hline $\mathrm{pH}$ & 5.0 & 9.0 \\
Nanoparticle mass / mg & 10.0 & 90.0 \\
Pre-concentration time / min & 4.0 & 10.0 \\
Elution time / min & 1.0 & 4.0 \\
Concentration of eluent / $\left(\mathrm{mol} \mathrm{L}^{-1}\right)$ & 1.0 & 3.0 \\
\hline
\end{tabular}

Study of univariate $\mathrm{pH}$ and point of zero charge (PZC)

The $\mathrm{pH}$ of the solution is one of the most important parameters affecting the efficiency of the MSPE. Thus, after the $2^{5-1}$ fractional factorial design and under optimized conditions of MSPE, the effect of $\mathrm{pH}$ on the preconcentration of $\mathrm{Pb}^{2+}$ ions onto the m-MWCNT@Si-SH nanocomposite was evaluated univariately from experiments carried out in the $\mathrm{pH}$ range of 2.0-9.0.

The PZC is an important parameter to assess the surface charge properties of adsorbents and to determine the electrophoretic mobility when the total net charge is zero. To measure the PZC, $20 \mathrm{~mL}$ of an aqueous solution of $0.1 \mathrm{~mol} \mathrm{~L}^{-1} \mathrm{NaCl}$ under different initial $\mathrm{pH}$ values $(2<\mathrm{pH}<12)$, adjusted by $\mathrm{NaOH}$ and $\mathrm{HCl}$ solutions, at concentrations equal to $0.1 \mathrm{~mol} \mathrm{~L}^{-1}$, were mixed with $20 \mathrm{mg}$ of the m-MWCNT@Si-SH nanocomposite, and the mixture was stirred for $24 \mathrm{~h}$ at room temperature. Subsequently, the adsorbent was separated from the solution with the aid of a magnet and the final $\mathrm{pH}$ was measured. The graph of the final $\mathrm{pH}$ (supernatant) versus initial $\mathrm{pH}$ was plotted and $\mathrm{pH}_{\mathrm{PZC}}$ was determined (Figure S1, Supplementary Information (SI) section).

\section{Sample preparation}

The method was successfully applied in tap and mineral water samples for the determination of $\mathrm{Pb}^{2+}$ ions. Tap water samples were obtained from laboratories of the Federal University of Grande Dourados, located in the city of Dourados, Brazil, while mineral water samples of three different brands were purchased in a local supermarket. The samples were acidified and filtered under vacuum using filter paper of porosity $0.16 \mathrm{~mm}$ and stored in a freezer until analysis. Before analysis by MSPE, the $\mathrm{pH}$ of all samples was adjusted to 4.0 using $\mathrm{HNO}_{3}$ and $\mathrm{NaOH} 1.0 \mathrm{~mol} \mathrm{~L}^{-1}$. 


\section{Results and Discussion}

\section{Characterization of the magnetic nanocomposite}

FTIR spectra can provide useful information to identify the presence of certain functional groups on the adsorbent surface, as well as confirm each step of the synthesis of the magnetic nanocomposite. As can be seen in all spectra (Figure 1), the broad bands around $3400 \mathrm{~cm}^{-1}$ can be attributed to the stretching vibrations of $\mathrm{OH}$ groups from water molecules adsorbed on the material, while the band close to $580 \mathrm{~cm}^{-1}$ is characteristic of the stretching vibration of $\mathrm{Fe}-\mathrm{O}-\mathrm{Fe}$, a feature of magnetite $\left(\mathrm{Fe}_{3} \mathrm{O}_{4}\right)$. The bands observed close to $1637 \mathrm{~cm}^{-1}$ can be attributed to $\mathrm{C}=\mathrm{C}$ bonds present in the MWCNT structure. Particularly, in spectra Figures $1 \mathrm{~b}$ and $1 \mathrm{c}$, the intense band observed at $1083 \mathrm{~cm}^{-1}$ can be attributed to the stretching vibrations of the $\mathrm{Si}-\mathrm{OH}$ and $\mathrm{Si}-\mathrm{O}-\mathrm{Si}$ bonds, proving the silica coating of the nanoparticles, whereas the low band intensity at $2350 \mathrm{~cm}^{-1}$ (spectrum at Figure 1d) can be attributed to $\mathrm{SH}$ groups from the 3-MPTMS modifier, confirming the functionalization of the adsorbent m-MWCNT@Si-SH with thiol groups. ${ }^{15,21}$

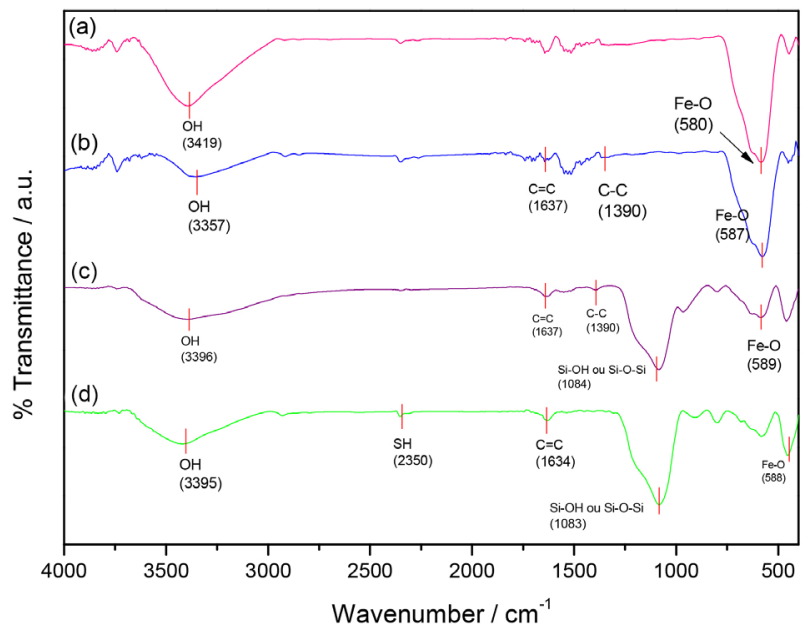

Figure 1. Infrared spectra of adsorbent materials: (a) $\mathrm{Fe}_{3} \mathrm{O}_{4}$; (b) m-MWCNT; (c) m-MWCNT@Si and (d) m-MWCNT@Si-SH.

X-ray diffractograms of $\mathrm{Fe}_{3} \mathrm{O}_{4}, \mathrm{~m}-\mathrm{MWCNT}$, m-MWCNT@Si, and m-MWCNT@Si-SH are shown in Figure 2. In Figure 2a, six characteristic peaks of the cubic structure of iron oxide $\left(\mathrm{Fe}_{3} \mathrm{O}_{4}\right)$ with respective $2 \theta$ angles of $30.03,35.57,43.23,53.66,57.22$, and $62.87^{\circ}$, and diffraction indices d(220), d(311), d(400), d(422), d(511), and d(440)), respectively, were observed and confirmed by the positions of the standard peaks from the XRD pattern of magnetite, according to JCPDS file No. 19-0629. Figure 2b shows a characteristic peak at $25.70^{\circ}$, with the diffraction index 002 , which can be attributed to the graphite crystalline phase present in the structure of the carbon nanotubes. However, in the spectra of Figure 2c, this peak decreases in intensity due to the coverage of silica, that in turn shows diffraction from $2 \theta=22$ to $28^{\circ}$, indicating a possible overlap of the characteristic peaks of MWCNTs and silica. In addition, the functionalization process on the surface of the nanoparticles with thiol groups (Figure 2d) does not alter the crystalline structure of the material, indicating that functionalization occurred in the mesoporous channels. ${ }^{15,24}$

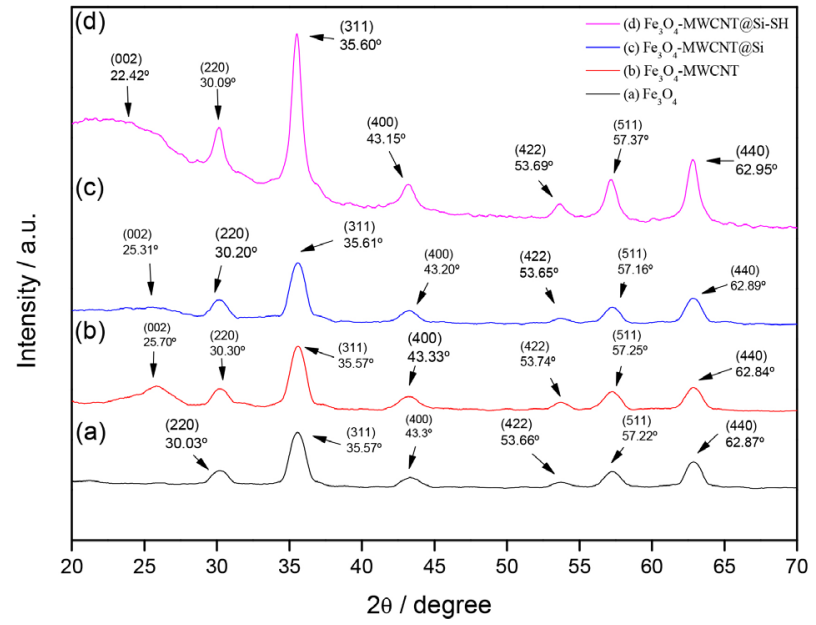

Figure 2. X-ray diffraction patterns of nanoparticles: (a) $\mathrm{Fe}_{3} \mathrm{O}_{4}$, (b) m-MWCNT, (c) m-MWCNT@Si and (d) m-MWCNT@Si-SH.

The textural parameters of the materials $\mathrm{Fe}_{3} \mathrm{O}_{4}$, m-MWCNT, m-MWCNT@Si, and m-MWCNT@Si-SH were analyzed and are listed in Table 2. A significant increase in the surface area of the adsorbents, accompanied by a decrease in the average pore diameter, can be observed and attributed to the insertion of magnetite in the carbon nanotubes filaments and to the silica coating. However, after the functionalization of the m-MWCNT@Si adsorbent with 3-MPTMS, a significant increase in pore volume can be observed due to the possible insertion of 3-MPTMS in the mesoporous channels of the adsorbent, corroborating the X-ray data provided previously. After functionalization with 3-MPTMS, a small increase in the average pore diameter can be observed for the m-MWCNT@Si-SH adsorbent, suggesting that the functional groups are distributed in the surface and mesoporous channels of adsorbent. It should be noted that the presence of mesopores in the adsorbent, classified by International Union of Pure and Applied Chemistry (IUPAC) as pores with a mean diameter between 2.0 and $50.0 \mathrm{~nm}$, and a high surface area, are considered among the most relevant characteristics for magnetic adsorbents used in metal determination via the MSPE method for sample preparation..$^{25}$

The morphologies of the materials were examined through the SEM images, as shown in Figure 3. Initially, 
Table 2. Textural parameters obtained for the $\mathrm{Fe}_{3} \mathrm{O}_{4}, \mathrm{~m}-\mathrm{MWCNT}, \mathrm{m}-\mathrm{MWCNT} @ \mathrm{Si}$, and m-MWCNT@Si-SH

\begin{tabular}{lcc}
\hline Material & Surface area $/\left(\mathrm{m}^{2} \mathrm{~g}^{-1}\right)$ & Total pore volume $/\left(\mathrm{cm}^{3} \mathrm{~g}^{-1}\right)$ \\
\hline $\mathrm{Fe}_{3} \mathrm{O}_{4}$ & 88.65 & 0.402 \\
m-MWCNT & 125.60 & 0.391 \\
m-MWCNT@Si & 349.20 & 0.629 \\
m-MWCNT@Si-SH & 256.20 & 0.618 \\
\hline
\end{tabular}

m-MWCNT: magnetic multiwalled carbon nanotubes.

in Figure 3a, an agglomerated structure, characteristic of $\mathrm{Fe}_{3} \mathrm{O}_{4}$ nanoparticles, can be observed, whereas in Figure $3 \mathrm{~b}$, the presence of filaments of the structure of the MWCNTs and the rough spherical structure of the $\mathrm{Fe}_{3} \mathrm{O}_{4}$ nanoparticles distributed in the carbon nanotube filaments can be observed. The insertion of silica in the m-MWCNT nanocomposite provided an increase in the degree of aggregation in the filaments of the nanotubes decorated with magnetite (Figure 3c). Although greater aggregation was observed for this material, an increase in surface area was also confirmed, as shown in Table 2, which favors the functionalization of organosilanes later. ${ }^{26}$ An increase in the dispersion of the MWCNTs after the insertion of thiol groups with silane coupling agents can be observed (Figure 3d), ensuring better distribution of the adsorbent in solution (m-MWCNT@Si-SH) and favoring the application of the adsorbent in MSPE methods. ${ }^{27}$

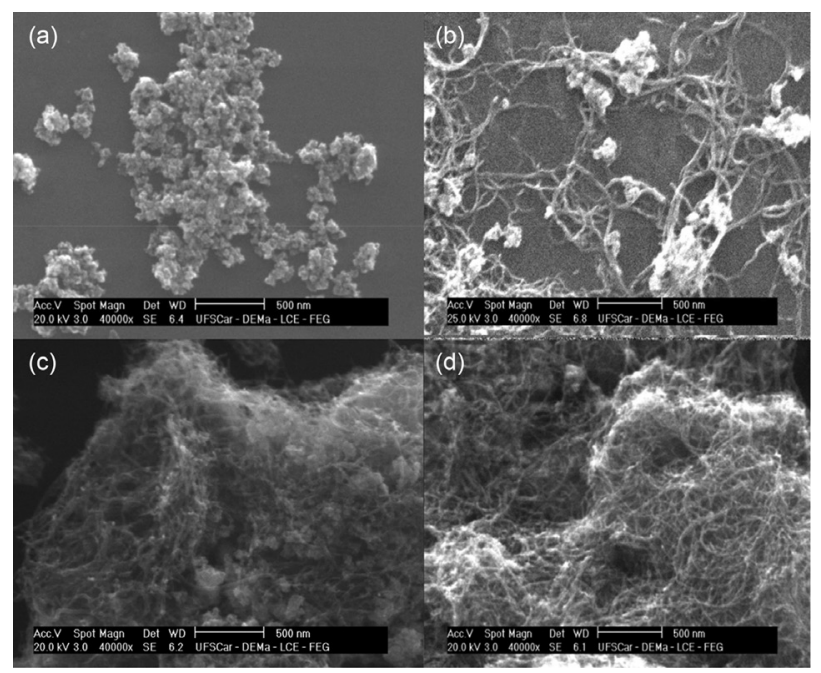

Figure 3. SEM micrographs of the: (a) $\mathrm{Fe}_{3} \mathrm{O}_{4}$; (b) m-MWCNT; (c) m-MWCNT@Si; (d) m-MWCNT@Si-SH.

From the semiquantitative analysis of the energydispersive X-ray spectroscopy (EDS) data (Table S1, SI section), the efficiency of the m-MWCNT@Si surface functionalization can be confirmed using the percentage values of $18.40,27.83,17.51,27.80$, and $6.74 \%(\mathrm{~m} / \mathrm{m})$ obtained for the elements $\mathrm{Fe}, \mathrm{O}, \mathrm{C}, \mathrm{Si}$, and $\mathrm{S}$, respectively, indicating the successful magnetization of the nanotubes (m-MWCNTs), as well as grafting with silica (m-MWCNT@Si) and functionalization with thiol groups through organosilane reagents (m-MWCNT@Si-SH).

The magnetic properties of the m-MWCNT@Si-SH nanocomposite were investigated using VSM (Figure 4). The magnetization saturation values of the adsorbents $\mathrm{Fe}_{3} \mathrm{O}_{4}$, m-MWCNT,m-MWCNT@Si, and m-MWCNT@Si-SH were found to be $89.80,43.13,7.94$, and $14.28 \mathrm{emu} \mathrm{g}^{-1}$, respectively. As seen, the significant decrease in saturation magnetization for the adsorbents can be attributed to the coating layer of magnetite particles and the modification with thiol groups by the addition of non-magnetic MPTMS, proving that the synthesis was successful. Although the magnetization saturation of the nanocomposite was lower than those of its precursors, it was suitable for MSPE and could be easily collected using the external magnetic.

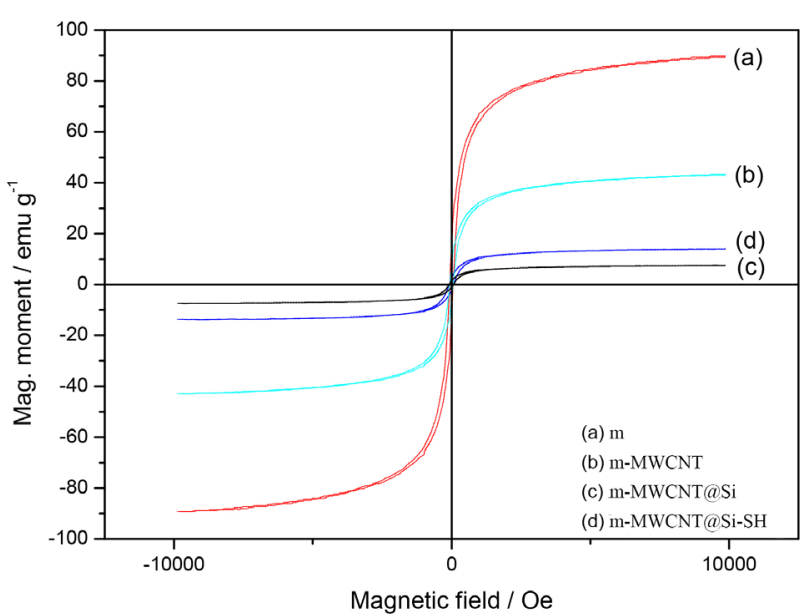

Figure 4. VSM magnetization curves of adsorbents.

Batch studies

\section{Kinetic studies}

For the kinetic studies, 20 mg of m-MWCNT@Si-SH was added to $10 \mathrm{~mL}$ of a solution containing $5 \mathrm{mg} \mathrm{L}^{-1}$ of $\mathrm{Pb}^{2+}$. The mixture was stirred for $1-90 \mathrm{~min}$. To better understand the mechanism of the adsorption kinetics of $\mathrm{Pb}^{2+}$ ions on m-MWCNT@Si-SH, models such as the pseudo-first-order, pseudo-second-order, Elovich, and intraparticle diffusion models were used. The parameters 
estimated from the models, along with the experimental sorption capacities, can be seen in Table S2 (SI section). The adsorption equilibrium rate was reached in $30 \mathrm{~min}$, with a maximum adsorption capacity of $1.995 \mathrm{mg} \mathrm{g}^{-1}$ for a $\mathrm{Pb}^{2+}$ concentration of $5 \mathrm{mg} \mathrm{L}^{-1}$. From the tabulated results, it was observed that the correlation coefficient from the pseudo-second-order model $\left(\mathrm{R}^{2}=0.999\right)$ was higher than that from the pseudo-first-order model $\left(\mathrm{R}^{2}=0.769\right)$. In addition, the theoretical sorption capacity estimated by the pseudo-second-order model proved to be very close to the experimental sorption capacity, which indicates that this model accurately describes the kinetics of adsorption of the proposed method, also suggesting a process of chemisorption between the $\mathrm{Pb}^{2+}$ ions and the magnetic adsorbent m-MWCNT@Si-SH. ${ }^{15,28}$ Furthermore, the kinetic data were assessed by the intraparticle diffusion model with the adsorption process divided into two stages: a short initial adsorption phase involving the external surface functional groups and a final phase involving a final equilibrium stage characterized by a plateau-like top. As can be seen in Table S2, good adjustments were observed for the two straight segments $\left(\mathrm{R}^{2}=0.999\right)$, suggesting that the sorption process is limited by diffusion in the film deposited on the external surface of the adsorbent and also by diffusion within the pores of the material, since the functional groups are expected to be present both on the surface and in the inside. ${ }^{15,29,30}$

\section{Adsorption isotherm}

The maximum adsorptive capacity of the m-MWCNT@Si-SH nanocomposite was evaluated by shaking $10.0 \mathrm{~mL}$ of $\mathrm{Pb}^{2+}$ solution at concentrations between 0.01 and $55 \mathrm{mg} \mathrm{L}^{-1}$ with 20 mg m-MWCNT@Si-SH for $30 \mathrm{~min}$. As can be seen in Figure S2 (SI section), the adsorption capacity increases significantly with increasing $\mathrm{Pb}^{2+}$ concentration $\left(0.01\right.$ to $\left.22 \mathrm{mg} \mathrm{L}^{-1}\right)$, reaching a maximum value of $6.236 \mathrm{mg} \mathrm{g}^{-1}$.

According to Table S3 (SI section), the dual-site Langmuir-Freundlich model shows a better fit $\left(\mathrm{R}^{2}=0.943\right)$ and lower error sum of square (SSE), confirming the existence of two types of adsorption sites with different binding energies related to the affinity of the $\mathrm{Pb}^{2+}$ ions by the adsorbent. This model allows attributing the binding sites capable of adsorbing $\mathrm{Pb}^{2+}$ ions on the surface of the adsorbent to the carboxylic and hydroxyl groups present in the structure of the carbon nanotubes, as they are the active sites with low affinity responsible for the retention of low concentrations of $\mathrm{Pb}^{2+}$; on the other hand, the active sites of the thiol group ( $\mathrm{SH}$ ) are the sites of greatest affinity, and are responsible for the sorption of $\mathrm{Pb}^{2+}$ in higher concentrations. From the sum of $b_{1}$ and $b_{2}$, the maximum estimated sorption capacity provides the maximum adsorption capacity of $5.869 \mathrm{mg} \mathrm{g}^{-1}$, close to the experimental value.

Multivariate optimization of MSPE for $\mathrm{Pb}^{2+}$ ion determination

The factors that play an important role in the extraction of $\mathrm{Pb}^{2+}$ using MSPE procedure was evaluated by means of a $2^{5-1}$ fractional factorial design. The assays were carried out by preconcentration of $45 \mathrm{~mL}$ of $\mathrm{Pb}^{2+}$ solution at $50 \mu \mathrm{g} \mathrm{L}^{-1}$ concentration. The influence of each factor in MSPE procedure was evaluated through analysis of variance $\left(\mathrm{R}^{2}=90.23 \%\right.$ ) (Table $\mathrm{S} 4$, SI section) at a confidence interval of $95 \%$ and graphically represented by a Pareto chart (Figure S3, SI section). It was observed (Figure S3) that the $\mathrm{pH}$ was the individual factor more statistically significant, in its lowest level, followed the factor nanoparticle mass. Although the interactions involving $\mathrm{pH}$ demonstrated to be statistically significant, the factors preconcentration and elution time, as well as, eluent concentration, were not significant when evaluated individually. Based on this and knowing that the $\mathrm{pH}$ of the solution plays a unique role in the adsorption process and extraction efficiency, since it affects the chemical properties of the adsorbent surface and enables complex formation between the ligand and $\mathrm{Pb}^{2+}$ ions, its effect was investigated later, in a univariate manner, within the range of 2.0-9.0. As mentioned, nanoparticle mass was the second most significant main factor, with an effect value equal to 2.771 . Thus, it was possible to observe that the greater the amount of material, the greater the amount of sites available for adsorption and, consequently, the greater the analytical signal. Therefore, the mass of $90 \mathrm{mg}$ was chosen as the best value for the further experiments. Although the preconcentration and elution time did not exert influence on the analytical response within the experimental domain, their interactions was very significant, revealing a synergistic effect between them, whereby shorter preconcentration and elution times significantly favored the adsorption of $\mathrm{Pb}^{2+}$ ions using MSPE as a method of sample preparation. Therefore, preconcentration and elution times of 4 and $1 \mathrm{~min}$, respectively, were selected for all experiments. As the eluent concentration also had no significant effect on the extraction of $\mathrm{Pb}^{2+}$ within the experimental domain, it was fixed at $1 \mathrm{~mol} \mathrm{~L}^{-1}$, considering that at high concentrations, the magnetic stability of the nanoparticle can be affected.

\section{Effect of $\mathrm{pH}$ on MSPE of $\mathrm{Pb}^{2+}$ ions}

As already mentioned, the $\mathrm{pH}$ of the solution is one of the most important parameters that influence MSPE. As shown in Figure 5, higher adsorption can be observed at $\mathrm{pH} 4.0$. 


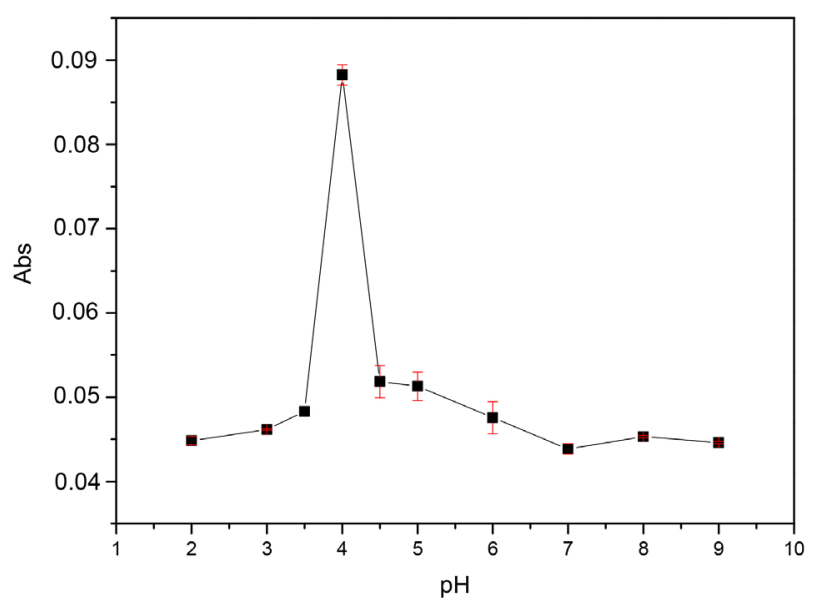

Figure 5. Effect of $\mathrm{pH}$ on the adsorption of $\mathrm{Pb}^{2+}$ ions on m-MWCNT@Si-SH as adsorbent.

The mechanism of $\mathrm{Pb}^{2+}$ adsorption depends on the thiol group present in the m-MWCNT@Si-SH nanocomposite, since it coordinates the dative covalent bond with $\mathrm{Pb}^{2+}$ ions. At low $\mathrm{pH}\left(\mathrm{pH}<\mathrm{pH}_{\mathrm{PZC}}\right)$, the surface of the nanocomposite is positively charged (+), decreasing the $\mathrm{Pb}^{2+}$ extraction due to similar charges. At $\mathrm{pH} 4.0\left(\mathrm{pH}>\mathrm{pH}_{\mathrm{PZC}}=3.54\right)$, the surface of m-MWCNT@Si-SH is negatively charged, favoring the extraction of $\mathrm{Pb}^{2+}$ ions by the thiol groups present in the material. In addition, as expected, for $\mathrm{pH}$ levels greater than 6.0 (in the alkaline range), there is a decrease in the absorbance values, probably due to the formation of lead hydroxide, as can be seen in the species distribution graph as a function of $\mathrm{pH}$ (Figure S4, SI section).

\section{Effect of potentially interfering ions}

The effect of potentially interfering ions on the extraction and preconcentration of $\mathrm{Pb}^{2+}$ onto the m-MWCNT@Si-SH nanocomposite in natural water samples was examined. Under optimized conditions, experiments were performed using a $50 \mu \mathrm{g} \mathrm{L}^{-1} \mathrm{~Pb}^{2+}$ solution in the presence of different concentrations of the interfering ions (Table S5, SI section).

The tolerance limit for this study was defined as the concentration of interfering ions that leads to an error of $\pm 10 \%$ in the determination of $\mathrm{Pb}^{2+}$ ions. Thus, the effects of common coexisting ions, such as $\mathrm{Na}^{+}, \mathrm{K}^{+}, \mathrm{Ca}^{2+}, \mathrm{Al}^{3+}$, $\mathrm{Cd}^{2+}, \mathrm{Fe}^{2+}, \mathrm{Cu}^{2+}, \mathrm{Ni}^{2+}$, and $\mathrm{Mn}^{2+}$, on the m-MWCNT@Si-SH adsorbent obtained through MSPE, were investigated. As seen in Table S5, the recovery of the analytical signal for $\mathrm{Pb}$ ions varied between 84.54 and $109.54 \%$, indicating good tolerance of the proposed method when applied in complex matrix samples. The low interference observed for these cations and anions in the $\mathrm{Pb}^{2+}$ ion preconcentration can be explained based on the high surface area of the adsorbent associated with the FAAS selective technique.

\section{Reusability of m-MWCNT@Si-SH}

Magnetic sorbents have low chemical stability since $\mathrm{Fe}_{3} \mathrm{O}_{4}$ magnetic particles can be damaged by analysis under drastic conditions and due to the solvent used for elution. In order to minimize the effect of this disadvantage, the modification of these sorbents with $\mathrm{SiO}_{2}$ and carbon nanotubes is a good approach but not definite solution. Therefore, reusability and stability tests of magnetic sorbents have proven to be important for this evaluation. The reusability and stability of the m-MWCNT@Si-SH nanocomposite were checked through ten consecutive adsorption/desorption cycles under optimized conditions. During eight consecutive cycles, the removal efficiencies of the $\mathrm{Pb}^{2+}$ ions ranged from 97.81 to $101.33 \%$ (Figure 6), proving that m-MWCNT@Si-SH showed good stability and high efficiency for repeated use up to at least eight cycles, without significant loss of the analytical signal.

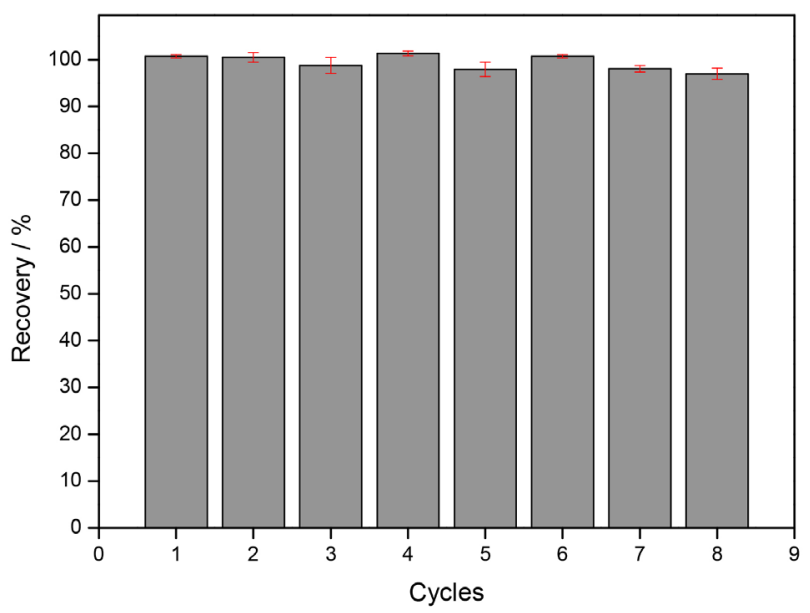

Figure 6. Reuse study of the m-MWCNT@Si-SH adsorbent subjected to ten adsorption-desorption cycles.

\section{Analytical performance of the MSPE/FAAS method}

Under optimized conditions, the analytical performance of the proposed method for determining $\mathrm{Pb}^{2+}$ ions using m-MWCNT@Si-SH as an adsorbent were evaluated from analytical curves constructed with the MSPE procedure and direct analysis via FAAS. The linearity achieved for $\mathrm{Pb}^{2+}$ ions was in the range of 1.86-100.00 $\mu \mathrm{g} \mathrm{L}^{-1}$ with determination coefficient $\mathrm{R}^{2}=0.997$ for $\mathrm{n}=8$, whereas the linearity achieved from the analytical curve without preconcentration was within the range of $0.1-10.0 \mathrm{mg} \mathrm{L}^{-1}$, with $R^{2}=0.996$ and $n=7$. Satisfactory preconcentration factors of 15.22 times were determined through the ratio between the angular coefficient of the curve with and without the preconcentration step. The limit of detection (LOD) and limit of quantification (LOQ), defined in accordance with 
IUPAC, ${ }^{31}$ yielding values equal to 0.557 and $1.860 \mu \mathrm{g} \mathrm{L}{ }^{-1}$, respectively. To assess the effect of the functionalization of the nanocomposite with thiol groups $(\mathrm{SH})$ from the 3-MPTMS organosilane, an analytical curve was built with a preconcentration step using the m-MWCNT@Si adsorbent, in linear range of 0.01-0.12 $\mathrm{mg} \mathrm{L}^{-1}$. From the LOD and angular coefficient observed for this analytical curve (Figure S5, SI section), it was possible to observe an increase of 3.53 times in the analytical signal for $\mathrm{Pb}^{2+}$ detection due to the insertion of the thiol group ( $\mathrm{SH}$ ) on the surface of the m-MWCNT@Si nanocomposite. In addition, the influence of carbon nanotubes present in the m-MWCNT@Si-SH nanocomposite on the sensitivity of the proposed method was evaluated via comparison of the angular coefficient of the analytical curves built using the adsorbents m-MWCNT@Si-SH and m@Si-SH, both in the linear range of 2.0 to $100.0 \mu \mathrm{g} \mathrm{L}-1$.

As can be seen in Table S6 (SI section), an increase of 1.47 times in the analytical signal was observed, proving that the presence of MWCNTs in the material contributes significantly to the functionalization of the adsorbent with thiol groups (SH), due to an increase in the surface area of the material besides to assist in its stability in the various extraction cycles. The precisions of the proposed method, determined as relative standard deviations (RSDs), were 2.33 and $2.1 \%$ for $\mathrm{Pb}^{2+}$ solutions at 10.0 and $120.0 \mu \mathrm{g} \mathrm{L} \mathrm{L}^{-1}$ concentrations, respectively. Other analytical parameters, relevant to the performance of the MSPE method, such as an enrichment factor $(\mathrm{EF})$, defined by the ratio between sample volume and eluent volume, of 22.5 and analytical frequency (AF) of 12 samples per $\mathrm{h}$, were obtained under optimized conditions.

Table 3 presents a brief comparison of the analytical performance of the proposed method for determining $\mathrm{Pb}^{2+}$ ions with those of some other methods previously reported in the literature that employed FAAS as the determination technique. As can be seen, the proposed method showed lower LODs and LOQs compared to the other methods and a reduced preconcentration time, favoring its $\mathrm{AF}$, and proving one of the main advantages of the MSPE method. In addition, its wide linear range allowed the determination of $\mathrm{Pb}^{2+}$ ions in different samples with accuracy.

\section{Determination of $\mathrm{Pb}^{2+}$ in real samples through MSPE/FAAS}

The proposed method was applied to determine $\mathrm{Pb}^{2+}$ ions in water samples, and an addition/recovery study by spiking known amounts of $\mathrm{Pb}^{2+}$ in the samples was carried out. The results are listed in Table 4. As can be seen, the percentage recovery varied from 90.33 to $109.53 \%$, which indicates good accuracy and precision with high potential of the proposed method for the preconcentration and determination of $\mathrm{Pb}^{2+}$ ions in real water samples. In addition, the results obtained by the proposed method are in agreement with those achieved by graphite furnace atomic absorption spectrometry (GF AAS), which was evidenced by the absence of statistical differences between the data (paired Student's $t$ test, 95\% confidence level, $t_{\text {calc }}=1.452$, lower than $t_{\mathrm{tab}}=2.201$ ) and the GF AAS method.

\section{Conclusions}

The synthesis of a new nanocomposite combining the chemical and physical properties of magnetite, silica, and organofunctionalized carbon nanotubes (m-MWCNT@Si-SH), and its application in the preconcentration of $\mathrm{Pb}^{2+}$ ions using MSPE, was presented for the first time in this paper. The proposed methodology proved to be fast, simple, reliable, and reproducible, with desirable characteristics for an extraction method,

Table 3. Comparison of the proposed method with recent studies to determine $\mathrm{Pb}^{2+}$ ions using MSPE

\begin{tabular}{|c|c|c|c|c|c|c|}
\hline Sorbent used in MSPE-FAAS method & $\begin{array}{l}\text { LOD / } \\
\left(\mu \mathrm{g} \mathrm{L}^{-1}\right)\end{array}$ & $\begin{array}{l}\mathrm{LOQ} / \\
\left(\mu \mathrm{g} \mathrm{L}^{-1}\right)\end{array}$ & $\mathrm{EF}$ & $\begin{array}{c}\text { Linear range / } \\
\left(\mu \mathrm{g} \mathrm{L}^{-1}\right)\end{array}$ & $\begin{array}{l}\text { Preconcentration } \\
\text { time / min }\end{array}$ & Reference \\
\hline SiMWCNT-PAN & 1.76 & 5.44 & 15 & - & 4 & 15 \\
\hline m-MWCNT & 1.0 & - & 390 & $5.0-200$ & 5 & 17 \\
\hline Magnetite particles modified with VSB & 17.00 & - & 7.3 & - & 60 & 18 \\
\hline PTh-DBSNa/ $\mathrm{Fe}_{3} \mathrm{O}_{4}$ & 0.7 & - & - & - & - & 32 \\
\hline mGO/SiO $\mathrm{S}_{2} @ \mathrm{coPPy}-\mathrm{Th}$ & 0.65 & - & - & - & 8.5 & 33 \\
\hline $\mathrm{CaFe}_{2} \mathrm{O}_{4}$-APTES-PA & 0.78 & - & - & $3.5-200$ & 10 & 34 \\
\hline $\mathrm{M}-\mathrm{PhCP}$ & 2.7 & 9.1 & - & - & 3 & 35 \\
\hline m-MWCNT@Si-SH & 0.56 & 1.86 & 20 & $1.8-100$ & 4 & this work \\
\hline
\end{tabular}

MSPE: magnetic solid-phase extraction; FAAS: flame atomic absorption spectrometry; LOD: limit of detection; LOQ: limit of quantification; EF: efficiency factor; MWCNT: multiwalled carbon nanotubes; PAN: 1-(2-pyridylazo)-2-naphthol; m-MWCNT: magnetic multiwalled carbon nanotubes; VSB: E-2-methoxy-4-(((3-(triethoxysilyl)propyl)imino)-methyl)phenol; PTh: polythiophene; DBSNa: sodium dodecyl benzene sulfonate; mGO: magnetic graphene oxide; PPy-Th: pyrrole-thiophene; APTES: 3-aminopropyl-triethoxysilane; PA: phthalic anhydride; M-PhCP: magnetic phosphorus-containing polymer. 
Table 4. Application of the method in the preconcentration of $\mathrm{Pb}^{2+}$ ions in water samples and the percentage of recovery from the addition and recovery test

\begin{tabular}{|c|c|c|c|c|c|}
\hline \multirow{2}{*}{ Sample } & \multirow{2}{*}{$\mathrm{Pb}^{2+}$ added $/\left(\mu \mathrm{g} \mathrm{L}^{-1}\right)$} & \multicolumn{2}{|c|}{ FAAS } & \multicolumn{2}{|c|}{ GF AAS } \\
\hline & & $\mathrm{Pb}^{2+}$ found / $\left(\mu \mathrm{g} \mathrm{L}^{-1}\right)$ & Recovery / \% & $\mathrm{Pb}^{2+}$ found / $\left(\mu \mathrm{g} \mathrm{L}^{-1}\right)$ & Recovery / \% \\
\hline \multirow{3}{*}{ Mineral water 1} & 0 & $1.90 \pm 0.55$ & - & $1.31 \pm 0.06$ & - \\
\hline & 5 & $6.33 \pm 0.78$ & 91.75 & $6.00 \pm 0.23$ & 95.11 \\
\hline & 20 & $19.78 \pm 0.33$ & 90.33 & $20.50 \pm 0.09$ & 96.20 \\
\hline \multirow{3}{*}{ Mineral water 2} & 0 & $2.05 \pm 0.78$ & - & $1.63 \pm 0.01$ & - \\
\hline & 5 & $6.40 \pm 0.22$ & 90.71 & $6.55 \pm 0.14$ & 98.78 \\
\hline & 20 & $23.26 \pm 0.55$ & 105.47 & $19.57 \pm 0.12$ & 90.46 \\
\hline \multirow{3}{*}{ Mineral water 3} & 0 & ND & - & $0.99 \pm 0.03$ & - \\
\hline & 5 & $5.38 \pm 0.11$ & 94.19 & $5.41 \pm 0.07$ & 90.41 \\
\hline & 20 & $19.30 \pm 1.67$ & 93.21 & $20.55 \pm 0.03$ & 97.89 \\
\hline \multirow{3}{*}{ Tap water } & 0 & $2.61 \pm 0.22$ & - & $1.69 \pm 0.29$ & - \\
\hline & 5 & $6.88 \pm 0.22$ & 90.44 & $6.46 \pm 0.13$ & 96.54 \\
\hline & 20 & $24.76 \pm 1.56$ & 109.53 & $21.61 \pm 0.03$ & 99.66 \\
\hline
\end{tabular}

The results are presented with the value of the mean standard deviation $( \pm)$ in triplicate $(n=3)$. FAAS: flame atomic absorption spectrometry; GF AAS: graphite furnace atomic absorption spectrometry; ND: not detected.

eliminating the filtration and centrifugation steps, and providing a clean and reliable sample for analysis by FAAS. The combination of MWCNT and silica to cover magnetic nanoparticles demonstrated some advantages, including high surface area $\left(256.20 \mathrm{~m}^{2} \mathrm{~g}^{-1}\right)$, notable adsorptive capacity ( $\left.6.236 \mathrm{mg} \mathrm{g}^{-1}\right)$, low cost, and high reuse capacity, since the adsorbent proved to be physically and chemically stable, supporting at least ten cycles of adsorptiondesorption without significant loss of the analytical signal. It should be noted that insertion of organosilane 3-MPTMS was efficient, increasing the adsorptive performance of the material against the removal of $\mathrm{Pb}^{2+}$ ions in water samples. Additionally, it could be considered a green method and environmentally friendly because of the use of magnetic nanoparticles based on $\mathrm{Fe}_{3} \mathrm{O}_{4}$ without the use of toxic solvents. Notably, despite the simplicity of the extraction procedure and the small amount of nanocomposite used, the LOD was lower than the permissible level of lead in drinking water according to the World Health Organization (WHO) report, demonstrating that it has great application potential for the extraction/removal of $\mathrm{Pb}^{2+}$ ions in different water samples. Thus, this work seeks to contribute to studies on the mechanism of removal of contaminants, aiming to find efficient and economical alternatives for the environmental problems caused by the disposal of effluents containing metal ions.

\section{Supplementary Information}

Supplementary data are available free of charge at http://jbcs.sbq.org.br as PDF file.

\section{Acknowledgments}

The authors acknowledge the financial support and fellowships of Coordenação de Aperfeiçoamento de Nível Superior (CAPES) Finance Code 001, Conselho Nacional de Desenvolvimento Científico e Tecnológico (CNPq) (project 407319/2016-6 and 307432/2017-3), Fundação Araucária do Paraná (163/2014), Instituto Nacional de Ciência e Tecnologia de Bioanalítica (INCT) (FAPESP Grant No. 2014/50867-3 and No. 465389/2014-7) and Universidade Estadual de Londrina (UEL).

\section{References}

1. Herrero-Latorre, C.; Barciela-García, J.; García-Martín, S.; Peña-Crecente, R. M.; Otárola-Jiménez, J.; Anal. Chim. Acta 2015, 892, 10.

2. Nekouei, S.; Nekouei, F.; Tyagi, I.; Agarwal, S.; Gupta, V. K.; Process Saf. Environ. Prot. 2016, 99, 175.

3. Alizadeh, T.; Hamidi, N.; Ganjali, M. R.; Rafiei, F.; J. Environ. Chem. Eng. 2017, 5, 4327.

4. Soylak, M.; Yilmaz, E.; Desalination 2011, 275, 297.

5. World Health Organization (WHO); Guidelines for DrinkingWater Quality Criteria and Other Supporting InformationAddendum, vol. 2, $2^{\text {nd }}$ ed.; WHO: Geneva, 1998, available at http://www.who.int/water_sanitation_health/dwq/2edaddvol2a. pdf, accessed in August 2021.

6. Conselho Nacional de Meio Ambiente (CONAMA); Resolução No. 357, de 17 de março de 2005, Dispõe sobre A Classificação dos Corpos de Água e Diretrizes Ambientais para o seu Enquadramento, bem como Estabelece as Condições e Padrões de Lançamento de Efluentes, e Dá outras Providências; available 
at https://www.icmbio.gov.br/cepsul/images/stories/legislacao/ Resolucao/2005/res_conama_357_2005_classificacao_corpos_ agua_rtfcda_altrd_res_393_2007_397_2008_410_2009_430_ 2011.pdf, accessed in August 2021.

7. Soylak, M.; Unsal, Y. E.; Food Chem. Toxicol. 2010, 48, 1511.

8. Baig, J. A.; Memon, H. D.; Bukhari, S. A. I.; Kazi, T. G.; Afridi, H. I.; Naseer, H. M.; Elci, L.; J. AOAC Int. 2017, 100, 1062.

9. Soylak, M.; Cay, R. S.; J. Hazard. Mater. 2007, 146, 142.

10. Šafaříková, M.; Šafařík, I.; J. Magn. Magn. Mater. 1999, 194, 108.

11. da Silva, A. K.; Sobieski, E.; Viana, L. H.; Lanças, F. M.; Nazario, C. E. D.; Sci. Chromatogr. 2016, 8, 239.

12. Jamshaid, T.; Neto, E. T. T.; Eissa, M. M.; Zine, N.; Kunita, M. H.; El-Salhi, A. E.; Elaissari, A.; TrAC, Trends Anal. Chem. 2016, 79, 344.

13. Rezaee, M.; Assadi, Y.; Hosseini, M.-R. M.; Aghaee, E.; Ahmadi, F.; Berijani, S.; J. Chromatogr. A 2006, 1116, 1.

14. Khazaeli, S.; Nezamabadi, N.; Rabani, M.; Panahi, H. A.; Microchem. J. 2013, 106, 147.

15. Khan, M.; Yilmaz, E.; Soylak, M.; J. Mol. Liq. 2016, 224, 639.

16. Ghasemi, E.; Heydari, A.; Sillanpää, M.; Eng. Agric. Environ. Food 2019, 12, 435.

17. Tarigh, G. D.; Shemirani, F.; Talanta 2013, 115, 744.

18. El-Sheikh, A. H.; Nofal, F. S.; Shtaiwi, M. H.; J. Environ. Chem. Eng. 2019, 7, 103229.

19. Alegre, D. C. M.; dos Santos, P. M.; de Oliveira, P. C.; Tarley, C. R. T.; Barros, W. R. P.; Corazza, M. Z.; Int. J. Environ. Anal. Chem. 2021, DOI: 10.1080/03067319.2021.1884237.
20. Huang, C.; Xie, W.; Li, X.; Zhang, J.; Microchim. Acta 2011, $173,165$.

21. Huang, C.; Hu, B.; Spectrochim. Acta, Part B 2008, 63, 437.

22. Mahmoud, M. E.; Amira, M. F.; Zaghloul, A. A.; Ibrahim, G. A. A.; Chem. Eng. J. 2016, 293, 200.

23. Statistica, version 10.0; StatSoft, Inc. Tulsa, USA, 2011.

24. Shen, Y.; Jiang, N.; Liu, S.; Zheng, C.; Wang, X.; Huang, T.; Guo, Y.; Bai, R.; J. Environ. Chem. Eng. 2018, 6, 5420.

25. ALOthman, Z. A.; Materials 2012, 5, 2874.

26. Diniz, K. M.; Tarley, C. R. T.; Microchem. J. 2015, 123, 185.

27. Nasir, A. N. M.; Yahaya, N.; Zain, N. N. M.; Lim, V.; Kamaruzaman, S.; Saad, B.; Nishiyama, N.; Yoshida, N.; Hirota, Y.; Food Chem. 2019, 276, 458.

28. Park, Y.; Kim, D.; J. Membr. Sci. 2018, 566, 1.

29. Pakade, V. E.; Monageng, S. M.; Tavengwa, N. T.; Asian J. Sci. Res. 2016, 9, 131.

30. Corazza, M. Z.; Ribeiro, E. S.; Segatelli, M. G.; Tarley, C. R. T.; Microchem. J. 2014, 117, 18.

31. Long, G. L; Wineforddner, J. D.; Anal. Chem. 1993, 55, 712.

32. Rajabi, M.; Abolhosseini, M.; Hosseini-Bandegharaei, A.; Hemmati, M.; Ghassab, N.; Microchem. J. 2020, 159, 105450.

33. Molaei, K.; Bagheri, H.; Asgharinezhad, A. A.; Ebrahimzadeh, H.; Shamsipur, M.; Talanta 2017, 167, 607.

34. Pirouz, M. J.; Beyki, M. H.; Shemirani, F.; Food Chem. 2015, 170, 131.

35. Yilmaz, E.; Alosmanov, R. M.; Soylak, M.; RSC Adv. 2015, 5, 33801 . 